\title{
Sole trisomy 6 an uncommon finding in pediatric acute myeloid leukemia, probably associated to bad prognosis
}

\author{
Sinhue Alejandro Brukman-Jimenez ${ }^{1,2}$, Lucina Bobadilla-Morales ${ }^{1,2}$, Jorge Román Corona-Rivera², \\ Pablo Alejandro Chávez-Panduro ${ }^{3}$, Citlalli Ortega-de-la-Torre', Uriel Francisco Santana-Bejarano², \\ Elizabeth Torres-Anguiano², Lucero Mendoza-Maldonado ${ }^{2}$, Fernando Antonio Sánchez-Zubieta ${ }^{1,3}$ \\ and Alfredo Corona-Rivera ${ }^{1,2^{*}}$ (i)
}

\begin{abstract}
Background: Acute leukemias represent the main malignancies occurring among children under the age of 15 years. Around 17\% corresponds to acute myeloid leukemia (AML). The cytogenetic analysis of bone marrow complements the diagnosis of hematological malignancies, therefore finding chromosomal aberrations provides a more reliable prognosis of the disease. Among the cytogenetic aberrations, sole trisomy is frequent in malignant neoplasias, but few cases related to AML have been reported.

Case presentation: We report a sole trisomy 6 in a pediatric patient diagnosed as AML M4 and poor progression. We carried out a literature review of AML patients with sole trisomy 6 and compared their evolution against AML patients with normal karyotype.

Conclusions: This is the first case of pediatric AML M4 with this cytogenetic finding. Sole trisomy 6 is infrequently reported in AML but scarce in pediatric cases. Based on overall survival analysis, we suggest that sole trisomy 6 could be associated with poor prognosis, in both, adult as well as pediatric AML.
\end{abstract}

Keywords: Sole trisomy 6, Acute myeloid leukemia, Overall survival

\section{Background}

Leukemia is the most frequent malignant neoplasia among the pediatric population. Acute leukemias represent $32 \%$ of malignancies occurring in children under the age of 15 years and around $17 \%$ of them are due to acute myeloid leukemia (AML) [1]. AML includes a genetically and clinically heterogeneous group classified by cytogenetic, immunophenotypic, and molecular findings in the

\footnotetext{
*Correspondence: alcoronar@gmail.com

${ }^{2}$ Instituto de Genética Humana "Dr. Enrique Corona Rivera", Laboratorio de Citogenética y Genómica, Centro Universitario de Ciencias de la Salud, Universidad de Guadalajara, Sierra Mojada Street \#950, CP-44340 Guadalajara, Jalisco, Mexico

Full list of author information is available at the end of the article
}

patient [2]. Trisomy of chromosome 6 as a sole cytogenetic abnormality has been observed in malignant neoplasias $[3,4]$. In the case of trisomies of AML, +8 is the most frequently observed, followed by trisomy $4,9,11,13$ and 21 [5], but trisomy 6 is infrequent [3, 4]. We scored 29 reported cases, 24 of them adults, and only 5 that corresponded to pediatric cases. The presence of AML-M4 cases was scarce in adults and not observed in pediatric cases. Prognosis of these cases has not been clarified [4]. We present a pediatric patient with AML-M4 and trisomy 6 as a sole cytogenetic abnormality confirmed by classical cytogenetics and molecular methods, literature update and prognostic implications. original author(s) and the source, provide a link to the Creative Commons licence, and indicate if changes were made. The images or other third party material in this article are included in the article's Creative Commons licence, unless indicated otherwise in a credit line to the material. If material is not included in the article's Creative Commons licence and your intended use is not permitted by statutory regulation or exceeds the permitted use, you will need to obtain permission directly from the copyright holder. To view a copy of this licence, visit http://creativecommons.org/licenses/by/4.0/. The Creative Commons Public Domain Dedication waiver (http://creativeco mmons.org/publicdomain/zero/1.0/) applies to the data made available in this article, unless otherwise stated in a credit line to the data. 


\section{Case report/case presentation}

A 14-year-old male patient, he was the third child of nonconsanguineous healthy parents without carcinogens exposition reported, from a dizygotic pregnancy, delivered by C-section, weight: $3350 \mathrm{~g}$, stature $52 \mathrm{~cm}$, with no otherwise pathological background, and not reported exposure to carcinogens, was admitted in 2016 with 8-day of cervical lymphadenopathy, intermittent fever, polydipsia, emesis, and hyporexia. Physical examination at the moment of admission, he showed mucotegumentary paleness, gingival hypertrophy, and palpable bilateral cervical lymph nodes of $15 \mathrm{~mm}$, as well as right supraclavicular palpable $15 \mathrm{~mm}$ lymph node; palpable hepatic flange at $2 \mathrm{~cm}$ below the costal ridge, not palpable spleen. Upon admission, his blood counts were: Hemoglobin: $5.7 \mathrm{~g} / \mathrm{dL}, \mathrm{WBC}: 244,000 / \mu \mathrm{L}$, Platelets: $52,000 / \mu \mathrm{L}$. The bone marrow aspirate showed hypercellularity, absent red and megakaryocytic series, increased white series with a predominance of monocytic series, and myeloblasts (Fig. 1b). By cytochemistry, myeloperoxidase positive blasts we reported. Immunophenotype reported a myeloid population of $72 \%$, expressing $\mathrm{CD} 13+, \mathrm{CD} 33+$,
HLA-DR+, CD38+, CD117+, and a second monocytic population of $20 \%$, expressing CD14+, CD33+, $\mathrm{CD} 36+, \mathrm{CD} 64+, \mathrm{CD} 38$ and CD45+. All the above data were compatible with Acute Myelomonocytic Leukemia or French-American-British (FAB) M4 classification [2]. He started chemotherapy, receiving cytarabine (100 $\mathrm{mg} / \mathrm{m}^{2} /$ dose $\left.\mathrm{q} 12 \mathrm{~h}\right)$, daunorubicin $\left(50 \mathrm{mg} / \mathrm{m}^{2} /\right.$ dose q48h) and etoposide (100 mg/m $/ \mathrm{m}^{2} /$ dose q24h). On day 2 , an increase in the leukocyte count was reported: 500,000/ $\mu \mathrm{L}$ with a monocytes predominance of $75 \%$; leukophoresis was indicated, and cytarabine induction was initiated. He died on day 3, with hyperleukocytosis of 728,000 $\mu / \mathrm{L}$, acute renal failure, and pulmonary leukostasis. In this study patient data were protected and maintained as anonymous. The parents gave their written informed consent to use clinical data.

\section{Chromosome and fluorescence in situ hybridization analysis}

The bone marrow sample was obtained for cytogenetic and molecular diagnosis. Chromosomal preparations were obtained from cell cultures of 0 and $24 \mathrm{~h}$ of

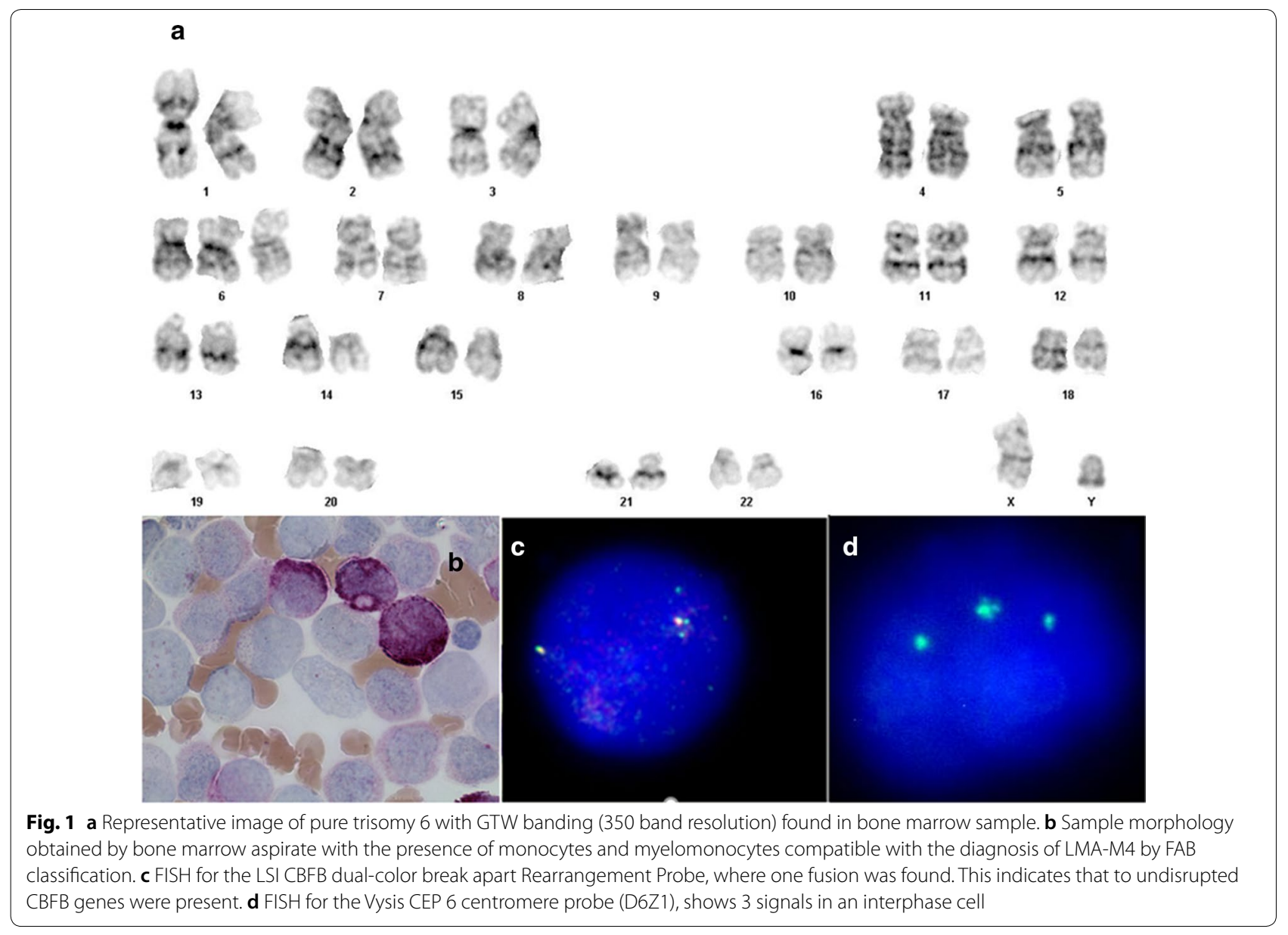


incubation cultured with RPMI, supplemented with L-glutamine, fetal bovine serum, and antibiotic. Chromosome banding was performed with trypsin and Wright solution. For the molecular diagnosis of trisomy 6, FISH was performed with the Vysis CEP 6 probe (D6Z1). Besides, Fluorescence In Situ Hybridization was performed for CBFB gene disruption from 16q22 chromosomal rearrangement with the LSI CBFB Dual Color Break Apart Probe (Vysis, cat. 05J65-001 (Fig. 1c). The finding of one red signal, one green signal, and one fusion is a representative finding of an abnormal chromosomal rearrangement, in this case, 2 fusions were found, it indicates a normal result, supporting the finding of sole trisomy 6 .

\section{Molecular diagnosis}

qPCR was performed to the search of inv(16)(p13.1q22) by CBFB-MYH11 fusion transcripts from cDNA using applied biosystems ${ }^{\mathrm{TM}}$ high capacity cDNA reverse transcription kit and Thermo Fisher Scientific CBFB-MYH11 fusion transcripts panel kit. The FLT3/ITD amplification was performed on a Proflex 96-well PCR system (Applied Biosystems) thermocycler using 11F (5'-6FAMCAA TTT AGG TAT GAA AGC C-3') and 12R (5'-GTA CCT TTC AGC ATT TTG AC-3') PCR primers. Capillary electrophoresis separations were performed using a 3130 Genetic Analyzer (Applied Biosystems) and GeneScan-500 LIZ size standard. The fragment analysis was carried out with Gene-Mapper v.3.5 software (Applied Biosystems).

To corroborate the absence of fusion genes involved in leukemia chromosomal rearrangements, we performed a nested multiplex RT-PCR (HemaVision ${ }^{\circledR}-\mathrm{HV} 01-28 \mathrm{~N}$, DNA Technology A/S) to the search of 28 common AML and ALL fusion transcripts. The procedure was described elsewhere [6]. The evaluated 28 fusion transcripts were: del1(p32) (STIL-TAL1), $\mathrm{t}(1 ; 11)$ (p32;q23) (MLL-EPS15), $\mathrm{t}(1 ; 11)(\mathrm{q} 21 ; \mathrm{q} 23)$ (MLL-MLLT11), $\mathrm{t}(1 ; 19)$ (q23;p13) (TCF3-PBX1), t(3;5)(q25;q34) (NPM1-MLF1), $\mathrm{t}(3 ; 21)$ (q26;q22) (RUNX1-MDS1/EVI1), t(4;11)(q21;q23) (MLL-AFF1), t(5;12)(q33;p13) (ETV6-PDGFRB), t(5;17) (q35;q21) (NPM1-RARA), t(6;9(p23;q34) (DEKNUP214), $\mathrm{t}(6 ; 11)(\mathrm{q} 27 ; \mathrm{q} 23) \quad$ (MLL-MLLT4), $\mathrm{t}(8 ; 21)(\mathrm{q} 22 ; \mathrm{q} 22)$ (RUNX1-RUNX1T1), $\mathrm{t}(9 ; 9)(\mathrm{q} 34 ; \mathrm{q} 34) \quad$ (SET-NUP214), $\mathrm{t}(9 ; 11)(\mathrm{p} 22 ; \mathrm{q} 23)$ (MLL-MLLT3), t(9;12)(q34;p13) (ETV6ABL1), $\mathrm{t}(9 ; 22)(\mathrm{q} 34 ; \mathrm{q} 11)$ (BCR-ABL1), $\mathrm{t}(10 ; 11)(\mathrm{p} 12 ; \mathrm{q} 23)$ (MLL-MLLT10), $\quad \mathrm{t}(11 ; 17)(\mathrm{q} 23 ; \mathrm{q} 21) \quad$ (MLL-MLLT6), $\mathrm{t}(11 ; 17)(\mathrm{q} 23 ; \mathrm{q} 21)$ (ZBTB16-RARA), $\mathrm{t}(11 ; 19)$ (q23;p13.1) (MLL-ELL), $\mathrm{t}(11 ; 19)(\mathrm{q} 23 ; \mathrm{p} 13.3)$ (MLL-MLLT1), $\mathrm{t}(12 ; 21)$ (p13;q22) (ETV6-RUNX1), t(12;22)(p13;q11) (ETV6MN1), t(15;17)(q24;q21) (PML-RARA), inv(16)(p13;q22) (CBFB-MYH11), t(16;21)(p11;q22) (FUS-ERG), t(17;19) (q22;p13) (TCF3-HLF), t(X;11)(q13;q23)(MLL-FOXO4). Any fusion genes were found in this probe.

\section{Statistical analysis}

Overall survival (OS) is defined as the time from the day of diagnosis to death or last visit [7]. Overall survival was calculated by methods of Kaplan \& Meier and compared between groups with the log-rank test [8]. The analyses were performed using SPSS software version 22 (SPSS, Chicago, IL, USA).

\section{Database research}

To establish the relationship found between the cytogenetic report (sole trisomy 6) and bone marrow morphology (AML), the search for previous reports with these same variants was carried out in Mitelman Database of Chromosome Aberrations and Gene Fusions in Cancer [9] (http://cgap.nci.nih.gov/Chromosomes/Mitel man), and the NCBI database (http://www.ncbi.nlm.nih. gov/pubmed) with the combination of the terms "Trisomy 6", "AML", and "M4". We found 29 previous reports of trisomy 6 and the morphological diagnosis of AML: 24 cases corresponded to adults and only 5 to pediatric patients (1 FAB M3, 1 M7 and 3 unclassified (Table 1).

\section{Results}

The observed karyotype from bone marrow aspirate was: $47, \mathrm{XX},+6[12 / 15] / 46, \mathrm{XX}[3 / 15]$. FISH studies revealed the presence of additional chromosome 6 centromere repetitive sequences signal in 143 out 200 cells: nuc ish(D6Z1) x3[143/200]/(D6Z1)x2 [57/200], and the absence of 16q22 chromosome rearrangements (Fig. 1a, c, d).

qPCR studies: CBFB-MYH11 fusion transcripts expression was not observed, in consequence, we concluded that inv16(p13.1q22) was not present. The FLT3/ITD amplification mutation was positive.

Nested multiplex PCR assay to detect 28 common fusion transcripts in AML and ALL was reported negative. This supports the absence of the most common chromosomal rearrangements in AML in our patient.

In Table 1, the reported cases with trisomy 6 as the sole chromosomal abnormality are summarized. 24 adults and 5 pediatric cases were scored.

To search the prognosis, we performed an OS analysis. In this context, Yu et al. [4], did not identify trisomy 6 as a prognosis marker. It also had been discussed that more studies were needed to elucidate the role of trisomy 6 in prognosis [10]. Due to there are no reports of trisomy 6 in LMA M4 pediatric population we tried to define if trisomy 6 could be a marker of poor prognosis. To determine the probable prognostic impact of this cytogenetic finding, we compared the available OS obtained from previous cases reported with sole trisomy 
Table 1 Cases of acute myeloid leukemia with sole trisomy 6 and their laboratory findings

\begin{tabular}{|c|c|c|c|c|c|c|c|c|c|c|}
\hline Case & Diagnosis & Karyotype & $\begin{array}{l}\text { Survival } \\
\text { (months) }\end{array}$ & Age (years) & Sex & $\mathrm{WBC}^{*}$ & $\mathrm{Hb}^{* *}$ & $\mathrm{PLT}^{* * *}$ & References & Country \\
\hline \multicolumn{11}{|c|}{ Adult cases } \\
\hline 1 & AML-NS & NA & 36 & 74 & $M$ & NA & NA & NA & Panani et al. [20] & Greece \\
\hline 2 & AML-M4 & $47, X X,+6[8 / 18]$ & 1 & 50 & $\mathrm{~F}$ & NA & NA & NA & Testa et al. [21] & USA \\
\hline 3 & AML-M5 & $47, X X,+6[58 / 58]$ & 4 & 24 & $\mathrm{~F}$ & NA & NA & NA & Weh et al. [22] & Germany \\
\hline 4 & AML-M2 & $47, X X,+6[2 / 7]$ & NA & 81 & $M$ & NA & NA & NA & Chan et al. [23] & Hong Kong \\
\hline 5 & AML-M2 & $47, X X,+6[3 / 8]$ & NA & NA & $\mathrm{F}$ & NA & NA & NA & Berger et al. [24] & France \\
\hline 6 & AML (M2) & $47, X Y,+6[15 / 21]$ & $>1$ & 55 & $M$ & NA & NA & NA & UKCCG [25] & U.K. \\
\hline 7 & AML (M5a) & $47, X X,+6[17 / 17]$ & $>15$ & 55 & M & NA & NA & NA & UKCCG [25] & U.K. \\
\hline 8 & AML-NS & $47, X X,+6[2 / ?]$ & 22 & 37 & $F$ & NA & NA & NA & UKCCG [25] & U.K. \\
\hline 9 & AML-M2 & $47, X X,+6[3 / 9] / 46, X X[6 /) 9]$ & 3 & 63 & $\mathrm{~F}$ & 4.8 & 13.5 & 6 & Jonveaux et al. [18] & France \\
\hline 10 & AML-M2 & $47, X X,+6[17 / 19] / 46, X X[2 / 19]$ & $1+$ & 28 & $\mathrm{~F}$ & 4 & 11 & 53 & Jonveaux et al. [18] & France \\
\hline 11 & AML-M4 & $47, X X,+6[19 / 30] / 46, X X[11 / 30]$ & 22 & 66 & $\mathrm{~F}$ & 2.6 & 8.1 & 51 & Mohamed et al. [11] & USA \\
\hline 12 & AML-M1 & $47, X X,+6[30 / 30]$ & 1 & 74 & M & 29.4 & 9.3 & 26 & Mohamed et al. [11] & USA \\
\hline 13 & AML-M1 & $47, X Y,+6[20 / 20]$ & 4 & 22 & M & 4.4 & 12.5 & 238 & Mohamed et al. [11] & USA \\
\hline 14 & AML-M1 & $47, X Y,+6[7 / 20] / 46, X Y[13 / 20]$ & 10 & 40 & $M$ & 86.5 & 11.1 & 63 & Mohamed et al. [11] & USA \\
\hline 15 & AML-MRC & $47, X X,+6[39 / 40] / 46, X X[1 / 40]$ & $>47$ & 37 & $F$ & 5.1 & 12.2 & 11 & Mohamed et al. [11] & USA \\
\hline 16 & AML-NS & $47, X X,+6[8 / 23] / 46, X X[15 / 23]$ & 27 & 41 & $\mathrm{~F}$ & NA & NA & NA & De Souza et al. [26] & Brazil \\
\hline 17 & AML-NS & $47, X X,+6$ & NA & NA & $\mathrm{F}$ & NA & NA & NA & $\begin{array}{l}\text { Kerndrup and Kjeldsen } \\
\text { [27] }\end{array}$ & Denmark \\
\hline 18 & AML-NS & $47, X X,+6[11]$ & NA & 61 & $F$ & NA & NA & NA & Beyer et al. [28] & Switzerland \\
\hline 19 & AML-M1 & $47, X X,+6[20]$ & 23 & 51 & M & 20.77 & 13.5 & 4 & Yu et al. [4] & South Korea \\
\hline 20 & AML-M2 & $47, X X,+6[20]$ & $>58$ & 25 & $\mathrm{~F}$ & 82.94 & 8 & 109 & Yu et al. [4] & South Korea \\
\hline 21 & AML-M4 & $47, X X,+6[4 / 20] / 46, X X,[16 / 20]$ & 3 & 82 & M & 5.08 & 6.4 & 21 & Yu et al. [4] & South Korea \\
\hline 22 & AML-M7 & $47, X X,+6[12 / 20] / 46, X X[8 / 20]$ & 1 & 21 & $\mathrm{~F}$ & 56.3 & 5.4 & 85 & Gupta et al. [10] & India \\
\hline 23 & AML-NS & $47, X X,+6$ & 1 & 50 & $\mathrm{~F}$ & NR & 8.5 & 11 & Aydin et al. [29] & Turkey \\
\hline 24 & AML-M5 & $47, X Y,+6$ & 3 & 75 & M & 103.8 & 7.3 & 80 & Manabe et al. [12] & Japan \\
\hline \multicolumn{11}{|c|}{ Pediatric cases } \\
\hline 25 & AML-NS & $47, X Y,+6$ & NA & 11 & M & NA & NA & NA & Philip et al. [13] & Denmark \\
\hline 26 & AML-NS & $47, X X,+6[8]$ & 27 & 8 & $\mathrm{~F}$ & 99 & NA & NA & Benedict et al. [14] & USA \\
\hline 27 & AML-(M3) & $47, X Y,+6$ & $>7$ & 8 & M & NA & NA & NA & UKCCG [25] & U.K. \\
\hline 28 & AML-M7 & $47, X X,+6[9 / 20] / 46, X X[11 / 20]$ & NA & 1 & M & 16.4 & 7.6 & 6 & McCullough et al. [15] & Ireland \\
\hline 29 & AML-NS & $47, X X,+6$ & 18 & 8 & $\mathrm{~F}$ & NA & NA & NA & Koh et al. [19] & South Korea \\
\hline 30 & AML-M4 & $47, X X,+6[12 / 15] / 46, X X[3 / 15]$ & 1 & 14 & M & 244 & 5.7 & 52 & Present report & \\
\hline
\end{tabular}

WBC *: White blood cells measured in $10^{9} / \mathrm{L} ; \mathrm{Hb}^{* *}$ : Hemoglobin measured in g/dL; PLT ***: Platelets measured in $10^{9} / \mathrm{L} ; \mathrm{AML}-\mathrm{NS}:$ Acute Myeloid Leukemia non otherwise specified by FAB classification; NA: Not available data. U.K.: United Kingdom; USA: United States of America

6 and AML patients $(A M L+T 6, n=24)$, including our case report, versus pediatric patients from our hospital with LMA M4 and normal karyotype (NK) $(\mathrm{n}=12)$ (Table 1). The median OS in AML + T6 was 18.6 months compared to 31.8 months in LMA-M4+NK. Differences between groups was calculated by mantel-cox test, and it was not significant $(\mathrm{p}=0.149)$ (Fig. $2 \mathrm{a}) . \mathrm{AML}+\mathrm{T} 6$ group was also compared to pediatric patients from our hospital with different types of AML $+\mathrm{NK}(\mathrm{n}=35$, FAB classification: $\mathrm{M} 1=2, \mathrm{M} 2=6, \mathrm{M} 3=5, \mathrm{M} 4=13, \mathrm{M} 5=7$, $\mathrm{M} 6=1, \mathrm{M} 7=1$, OS 1 to 58 months). In $\mathrm{AML}+\mathrm{T} 6$, the median OS was 17.9 months compared to 30.6 months in $A M L+N K$, which were significant by mantel-cox test of $\mathrm{p}=0.039$ (Fig. 2b). Furthermore, we compared adult patients from Table $1(n=20)$ versus pediatric $\mathrm{AML}+\mathrm{NK}$ group observing a significant difference (mantel-cox test, $\mathrm{p}=0.049$ ) (Fig. 2c); OS of patients with $\mathrm{AML}+6$ childhood $(\mathrm{n}=4)$ previously reported compared to childhood patients from our hospital with AML and normal karyotype (AML + NK) were not significant.

\section{Conclusion}

In our review, twenty-nine AML cases with trisomy 6 as a sole cytogenetic aberration (Table 1) had been previously reported. Most of the cases were adults (24/29, age range 21-82 years old) and only a 6 pediatrics (age range 

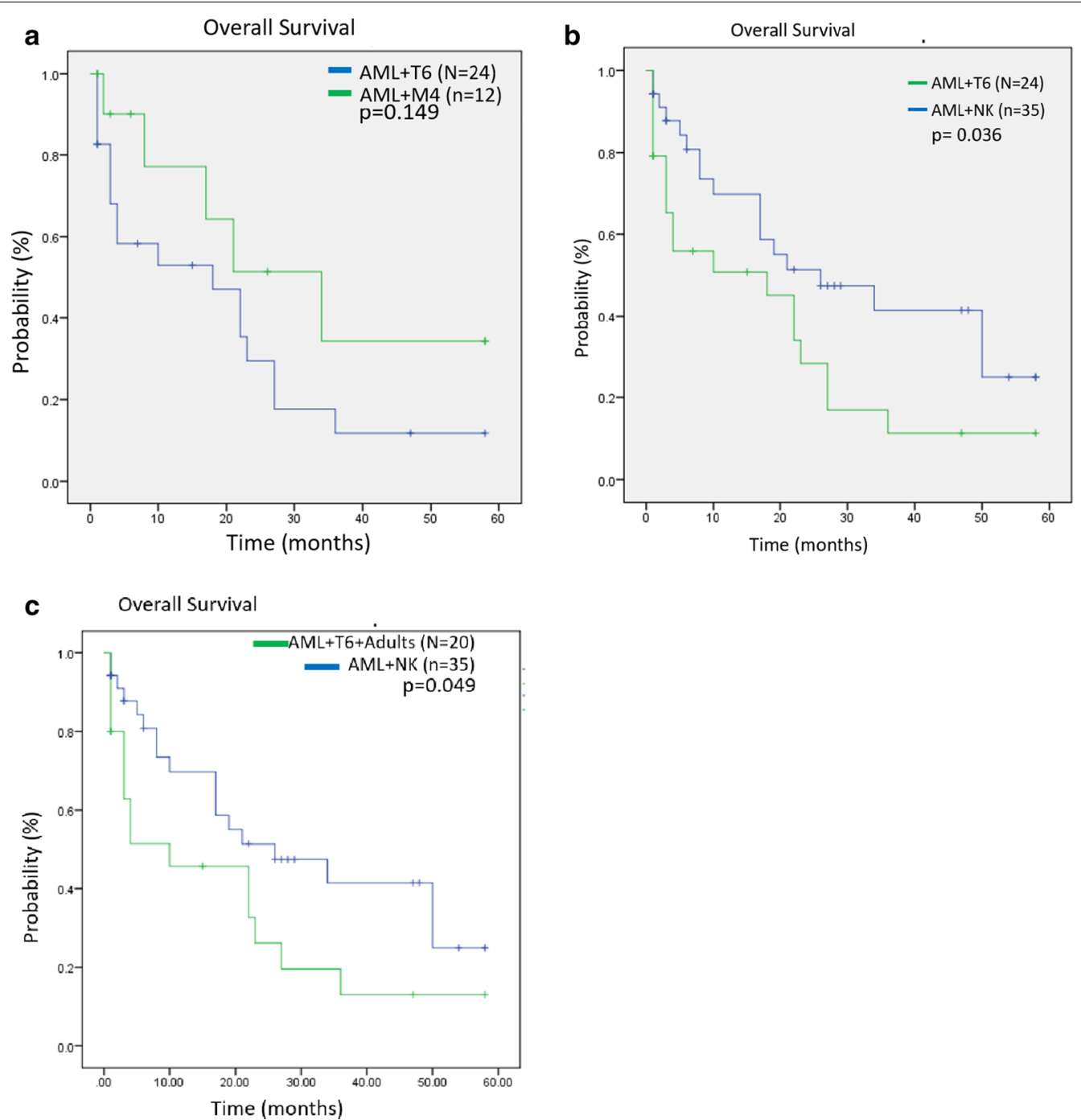

Fig. 2 Overall survival (OS) by karyotype condition calculated by Mantel-Cox test. a OS of patients previously reported with AML and trisomy 6 $(A M L+T 6)$ compared to childhood patients from our hospital with AML M4 and normal karyotype (AML-M4+NK). b OS of patients with AML +T6 compared to childhood patients from our hospital with AML and normal karyotype (AML + NK). c OS of patients with AML +T6 adults $(n=20)$ previously reported compared to childhood patients from our hospital with AML and normal karyotype (AML+NK)

1-14 years old) including the present case. There was no predominance of sex. Ten of them were diagnosed as AML but no FAB classification was specified, four were FAB classified as AML-M1, one as AML-MRC, five as AML-M2, one as AML-M3, four as AML-M4, three as AML-M5 and two as AML-M7. With this variety of e, we cannot infer a possible association of morphology FAB classification and trisomy 6 as seen previously $[4,11,12]$. As the few reported cases showed, trisomy 6 is presented predominantly in adults. Our case is the first pediatric (14 years old) with AML-M4. Interestingly, in all AMLM4 cases including the present case, a proportion of normal cells without +6 was observed, and the proportion of trisomy 6 cells varied from 20 to $80 \%$. Additionally, it is to be noted that among them, the two patients with the highest percentage of trisomy 6 cells had the lowest chances of survival. Although this could suggest a prognostic factor of this karyotype in AML-M4, nevertheless, more cases are needed to elucidate this topic.

In the previous sole trisomy 6 cases, only 3 patients were reported with AML M4, and it was presented in adults 2 of the reports refer to the cytogenetic finding as a poor prognosis factor when having a survival factor of 1-3 months. To date, few cases have been reported with this chromosomal complement in the presence of AML and there is no case of trisomy 6 in the pediatric 
population in the presence of AML M4. Evidence in our case comes from centromere FISH studies, that exhibit 3 centromere sequence 6 chromosome signals. Additionally, no other alteration was found in the 28 genes analyzed by nested multiplex PCR. Also, we ruled out the presence of FAB condition Ma eo, because CBFB FISH exhibited a normal pattern. Previous pediatric reported cases were unable to perform these analyses $[13,14]$, just one case [15], used WCP 6 chromosome to confirm the presence of +6 , to complement the cytogenetical finding. It seems that the sole +6 condition yield to a particular myeloid entity.

Yu et al. [4], concluded that more studies are needed to establish the clonality of AML with +6 . To our knowledge, there have been no reports with additional molecular studies like ours. FLT3 (the Fms-like tyrosine kinase 3) gene encodes a receptor that supports the survival, proliferation, and differentiation of hematopoietic progenitor cells in the bone marrow. In patients with a diagnosis of AML may behave mutations in FLT3 gene. Two kinds of mutations are more frequent: internal tandem duplications (ITDs) of juxtamembrane domain and missense point mutations, in the tyrosine kinase domain [16]. ITDs are associated with poor prognosis [17]. Our patient was reported as FLT3 positive, giving a poor prognosis joined with the age at the diagnosis moment probably gives a fatal outcome. It is too early to suggest a possible association between sole trisomy 6 in AML and FLT3 ITDs, additional molecular studies are required to investigate the FLT3 status in these patients, but in our patient, this could be associated to bad prognostic.

Pure trisomy 6 is a chromosomal abnormality rarely reported as a cytogenetic finding in malignant hematologic neoplasms [15]. It has been suggested that this chromosomal rearrangement could belong to a poor prognosis subgroup related to MDS and associated with cytopenia and bone marrow hypoplasia [11]. Our statistical evaluation using all de available OS previously reported in AML patients with sole trisomy 6 against a comparative group of patients from our hospital with different types of AML but normal karyotype, contribute to the hypothesis previously suggested that trisomy 6 in AML could be related to bad prognosis in patients with this unusual cytogenetic finding.

The effect of an extra copy of a complete chromosome on the development of leukemogenesis is unknown, but some theories could explain its effects. The first is the direct effect of gene dosage generating an overexpression, and the second is the presence of cryptic gene rearrangements or gene mutations in the extra chromosome [15]. Following the suggestion of this theory, the search for multiple nested RT-PCR fusion genes, HemaVision ${ }^{\circledR}$ kit, was performed to search the 28 most common fusion genes, which was reported as negative. On the other hand, this clonal cytogenetic abnormality is reported with poor treatment response and poor survival [18], probably linked with the primitive nature of blasts [11]. Our patient wasn't positive to HLA-DR and CD34 as other reports $[10,30]$. In a pediatric AML case study by microarrays including a case with trisomy 6 , Koh et al. [19], proposed than a poor prognosis related to this aneuploidy in AML could be due to candidate IRF4 (6p25.3) and DEK (6q22.3) genes associated to leukemogenesis.

In summary, sole +6 condition may yield to a particular myeloid entity. Sole trisomy 6 has been reported in multiple hematologic alterations, such as aplastic anemia and myeloproliferative syndromes, but in a few cases of primary acute myeloid leukemia, and this is the first case of reported infantile AML M4. Due to the evolution described in this case and survival reported in patients with sole trisomy 6 against normal karyotype, the finding of pure trisomy 6 could be probably attributed to poor prognosis in AML, in both, adults and children. Further studies will elucidate the clinical effect of an extra chromosome 6 in AML and its significance.

\section{Abbreviations \\ AML: acute myeloid leukemia; RT-PCR: reverse transcription polymerase chain reaction; $\mathrm{Hb}$ : hemoglobin measured in $\mathrm{g} / \mathrm{dL}$; OS: overall survival; ITD's: internal tandem duplications; FAB: the French-American-British; AML-M4: acute myeloid leukemia M4 by FAB; WBC: white blood cells measured in $10^{9} / \mathrm{L} ; \mathrm{LOH}$ : loss of heterozygosity; AML + T6: acute myeloid leukemia and trisomy 6; FLT-3: the Fms-like tyrosine kinase 3.}

\section{Acknowledgements}

The authors appreciate the support provided by the Unit of Cytogenetics and Hematology Oncology Service staff, from the Nuevo Hospital Civil "Dr Juan I. Menchaca".

\section{Authors' contributions}

$A C R, J R C R$, COdIT, and LBM, performed the cytogenetic studies in the present case and collected the data relative to this case report. SABJ, UFSB, ETA and LMM did the molecular cytogenetic analysis and interpretation. SABJ, FASZ and PACP collected clinical data necessary for OR calculation. SABJ, ACR and PACP drafted the paper and all authors contributed to the finalizing of the manuscript. All authors read and approved the final manuscript.

\section{Funding}

The present study was partially supported by the National Council of Science and Technology (CONACYT, México), PhD Human Genetics Doctoral Program (University of Guadalajara).

\section{Availability of data and materials}

The datasets generated and/or analyzed during the current study are not publicly available due because the data of the patients treated at the reference institution, are only available for use within the institution, but are available from the corresponding author on reasonable request.

\section{Ethics approval and consent to participate}

This manuscript was approved by the Ethics Committee of the New Civil Hospital "Juan I. Menchaca", for publication with consent to reporting findings in tissue. 


\section{Consent for publication}

The parents gave their written informed consent to further use of data.

\section{Competing interests}

The authors of this paper have no conflicts of interest, including specific financial interests, relationships, and/or affiliations relevant to the subject matter or materials included.

\begin{abstract}
Author details
${ }^{1}$ Unidad de Citogenética, Servicio de Hematología y Oncología Pediátrica, División de Pediatría, Nuevo Hospital Civil de Guadalajara,"Dr. Juan I. Menchaca", Guadalajara, Jalisco, Mexico. ${ }^{2}$ Instituto de Genética Humana "Dr. Enrique Corona Rivera", Laboratorio de Citogenética y Genómica, Centro Universitario de Ciencias de la Salud, Universidad de Guadalajara, Sierra Mojada Street \#950, CP-44340 Guadalajara, Jalisco, Mexico. ${ }^{3}$ Servicio de Hematología y Oncología Pediátrica, División de Pediatría, Nuevo Hospital Civil de Guadalajara, "Dr. Juan I. Menchaca”, Guadalajara, Jalisco, Mexico.
\end{abstract}

Received: 20 May 2020 Accepted: 12 August 2020

Published online: 04 September 2020

\section{References}

1. Horner MJ, Ries LA, Krapcho M, et al. SEER cancer statistics review, 1975-2006. Bethesda, MD: National Cancer Institute; 2009.

2. Katabi N, Lewis JS. Update from the 4 th edition of the world health organization classification of head and neck tumours: what is new in the 2017 WHO blue book for tumors and tumor-like lesions of the neck and lymph nodes. Head Neck Pathol. 2017;11(1):48-54. https://doi. org/10.1007/s12105-017-0796-z.

3. Heim S, Mitelman F. Numerical chromosome aberrations in human neoplasia. Cancer Genet Cytogenet. 1986;22:99-108.

4. Yu S, Kwon MJ, Lee ST, et al. Analysis of acute myeloid leukemia in Korean patients with sole trisomy 6. Ann Lab Med. 2014;34(5):402-4.

5. Swerdlow SH, Campo E, Harris NL, et al. WHO classification of tumours of haematopoietic and lymphoid tissues. 4th ed. Lyon: IARC; 2008.

6. Bobadilla-Morales L, Pimentel-Gutiérrez HJ, Gallegos-Castorena S, Paniagua-Padilla JA, Ortega-de-la-Torre C, Sánchez-Zubieta F, Silva-Cruz R, Corona-Rivera JR, Zepeda-Moreno A, González-Ramella O, Corona-Rivera A. Pediatric donor cell leukemia after allogeneic hematopoietic stem cell transplantation in AML patient from related donor. Mol Cytogen. 2015;8:5. https://doi.org/10.1186/s13039-014-0105-4

7. Charafeddine KM, Hatoum HA, Otrock ZK, Mahfouz RA, Salem ZM, Shamseddine AI, Taher AT, El-Saghir NS, Bazarbachi A. Long-term outcome of adult acute lymphoblastic leukemia in Lebanon: a single institution experience from the American University of Beirut. Hematol Oncol Stem Cell Ther. 2009;2(2):333-9.

8. Kaplan ER, Meier P. Non-parametric estimation from in complete observations. J Am Stat Assoc. 1958;53:457-81.

9. Mitelman Database of Chromosome Aberrations and Gene Fusions in Cancer. In: Mitelman F, Johansson B, Mertens F, editors. 2020. https://mitel mandatabase.isb-cgc.org.

10. Gupta M, Radhakrishnan N, Mahapatra M, et al. Trisomy chromosome 6 as a sole cytogenetic abnormality in acute myeloid leukemia. Turk J Haematol. 2015;32(1):77-9.

11. Mohamed AN, Varterasian ML, Dobin SM, et al. Trisomy 6 as a primary karyotypic aberration in hematologic disorders. Cancer Genet Cytogenet. 1998;106(2):152-5 (Review)

12. Manabe M, Asada R, Hagiwara Y, Momose D, Sugano Y, Mazaki T, Koh KR. Trisomy 6 as the sole stemline abnormality in a patient with acute monocytic leukemia: a case report. Am J Blood Res. 2018;8(1):1-4 (eCollection 2018).

13. Philip P, Krogh Jensen M, Killmann SA, Drisvholm A, Hansen NE. Chromosomal banding patterns in 88 cases of acute nonlymphocytic leukemia. Leuk Res. 1978;2:201-12.

14. Benedict WF, Lange M, Greene J, et al. Correlation between prognosis and bone marrow chromosomal patterns in children with acute non lymphocytic leukemia: similarities and differences compared to adults. Blood. 1979;54(4):818-23.

15. McCullough SJ, Neat MJ, Power M, et al. Trisomy 6 in a child with acute megakaryoblastic leukemia (AML-M7). Cancer Genet Cytogenet. 2004;154(2):190-2.

16. Gilliland DG, Griffin JD. The roles of FLT3 in hematopoiesis and leukemia. Blood. 2002:100(5):1532-42.

17. Nakao M, Yokota S, Iwai T, Kaneko H, Horiike S, Kashima K, Sonoda Y, Fujimoto T, Misawa S. Internal tandem duplication of the flt3 gene found in acute myeloid leukemia. Leukemia. 1996;10(12):1911-8.

18. Jonveaux P, Fenaux P, Berger R. Trisomy 6 as the sole chromosome abnormality in myeloid disorders. Cancer Genet Cytogenet. 1994;74(2):150-2.

19. Koh KN, Lee JO, Seo EJ, Lee SW, Suh JK, Im HJ, Seo JJ. Clinical significance of previously cryptic copy number alterations and loss of heterozygosity in pediatric acute myeloid leukemia and myelodysplastic syndrome determined using combined array comparative genomic hybridization plus single-nucleotide polymorphism microarray analyses. J Korean Med Sci. 2014;29(7):926-33.

20. Panani A, Papayannis AG, Sioula E. Chromosome aberrations and prognosis in preleukaemia. Scand J Haematol. 1980;24(2):97-100. https://doi. org/10.1111/j.1600-0609.1980.tb02350.x.

21. Testa JR, Misawa S, Oguma N, Van Sloten K, Wiernik PH. Chromosomal alterations in acute leukemia patients studied with improved culture methods. Can Res. 1985:45(1):430-4.

22. Weh HJ, Kuse R, Hoffmann R, Seeger D, Suciu S, Kabisch H, et al. Prognostic significance of chromosome analysis in de novo acute myeloid leukemia (AML). Blut. 1988:56:19-26.

23. Chan LC, Kwong YL, Liu HW, Chan TK, Todd D, Ching LM. Cytogenetic analysis of hematologic malignancies in Hong Kong. A study of 98 cases. Cancer Genet Cytogenet. 1992;62(2):154-9. https://doi.org/10.1016/01654608(92)90255-7.

24. Berger R, Le Coniat M, Derré J, Flexor MA. Loss of chromosome 22 in patients with refractory anemia with excess of blasts (RAEB) in transformation and acute leukemia after RAEB. Cancer Genet Cytogenet. 1992:61:210-2.

25. United Kingdom Cancer Cytogenetics Group (UKCCG). Primary, single, autosomal trisomies associated with haematological disorders. Leuk Res. 1992;16(9):841-51. https://doi.org/10.1016/0145-2126(92)90030-b.

26. de Souza Fernandez T, Ornellas MH, Otero de Carvalho L, Tabak D, Abdelhay E. Chromosomal alterations associated with evolution from myelodysplastic syndrome to acute myeloid leukemia. Leuk Res. 2000:24(10):839-48. https://doi.org/10.1016/s0145-2126(00)00056-4.

27. Kerndrup GB, Kjeldsen E. Acute leukemia cytogenetics: an evaluation of combining G-band karyotyping with multi-color spectral karyotyping. Cancer Genet Cytogenet. 2001;124(1):7-11. https://doi.org/10.1016/ S0165-4608(99)00223-X.

28. Beyer V, Castagné C, Mühlematter D, Parlier V, Gmür J, Hess U, Kovacsovics T, Meyer-Monard S, Tichelli A, Tobler A, Jacky E, Schanz U, Bargetzi M, Hagemeijer A, de Witte T, van Melle G, Jotterand M. Systematic screening at diagnosis of-5/del(5)(q31), -7, or chromosome 8 aneuploidy by interphase fluorescence in situ hybridization in 110 acute myelocytic leukemia and high-risk myelodysplastic syndrome patients: concordances and discrepancies with conventional cytogenetics. Cancer Genet Cytogenet. 2004;152(1):29-41. https://doi.org/10.1016/j.cancergencyto.2003.10.005.

29. Aydın MS, Bozkurt S, Güneş G, Malkan ÜY, Aslan T, Etgül S, BüyükaşıkY, Haznedaroğlu iC, Sayınalp N, Göker H, Demiroğlu H, Özcebe OI, Aksu S. Solelnfrequent karyotypic aberration trisomy 6 in a patient with acute myeloid leukemia and breast cancer in remission. Turk J Haematol. 2017;34(1):103-4. https://doi.org/10.4274/tjh.2016.0030.

30. Moormeier JA, Rubin CM, Le Beau MM, Vardiman JW, Larson RA, Winter JN. Trisomy 6: a recurring cytogenetic abnormality associated with marrow hypoplasia. Blood. 1991;77(6):1397-8.

\section{Publisher's Note}

Springer Nature remains neutral with regard to jurisdictional claims in published maps and institutional affiliations. 